\title{
Excitonic Energy Transfer within InP/ZnS Quantum Dot Langmuir- Blodgett Assemblies
}

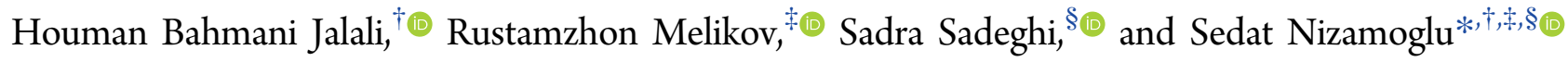 \\ ${ }^{\dagger}$ Department of Biomedical Science and Engineering, Koç University, Istanbul 34450, Turkey \\ ${ }^{\ddagger}$ Department of Electrical and Electronics Engineering, Koç University, Istanbul 34450, Turkey \\ ${ }^{\S}$ Department of Material Science and Engineering, Koç University, Istanbul 34450, Turkey
}

Supporting Information

ABSTRACT: Interparticle energy transfer offers great promise to a diverse range of applications ranging from artificial solar energy harvesting to nanoscale rulers in biology. Here, we assembled $\mathrm{InP} / \mathrm{ZnS}$ core/shell quantum dot monolayers via the Langmuir-Blodgett technique and studied the effect of $\mathrm{ZnS}$ shell thickness on the excitonic energy transfer within these core/shell quantum dots. Three types of InPbased core/shell quantum dot Langmuir-Blodgett assemblies with different $\mathrm{ZnS}$ shell thicknesses were assembled. The structural and optical properties of colloidal quantum dots reveal the successful multiple $\mathrm{ZnS}$ shell growth, and atomic force microscopy studies show the smoothness of the assembled monolayers. Time-resolved photoluminescence (PL) and fluorescence lifetime imaging microscopy (FLIM)

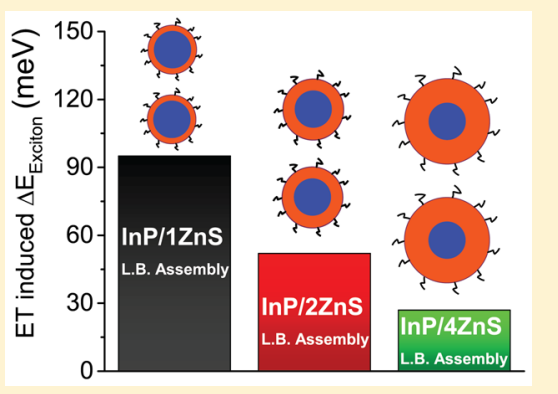
studies of the thick-shell QD monolayer reveal narrower lifetime distribution in comparison with the thin-shell QD monolayer. The interparticle excitonic energy transfer was studied by spectrally resolved PL traces, and higher energy transfer was observed for the thin-shell InP/1ZnS QD monolayer. Finally, we calculated the average exciton energy and indicated that the energy transfer induced exciton energy shift decreased significantly from 95 to $27 \mathrm{meV}$ after multiple $\mathrm{ZnS}$ shell growth.

\section{INTRODUCTION}

Excitonic energy transfer (ET) plays a significant role for light harvesting in the natural and artificial photovoltaic and optoelectronic systems and in understanding nanoscale interactions in living systems as well. ${ }^{1-11}$ Efficient and fast transport mechanism of the Förster resonance energy transfer (FRET) developed the so-called "FRET technology", in which excitons migrate via long-range dipole-dipole interactions. ${ }^{12,13}$ Recently, semiconductor quantum dots (QDs) have drawn attention for FRET applications due to their broad absorption spectra, large absorption cross section, size-tunable emission band, and long fluorescence lifetimes. Understanding the mechanisms of excitonic ET in QD-QD systems can provide new insights for the optimal design of artificial light-harvesting systems. $^{14}$ QD-QD excitonic ET requires excitation and absorption spectral overlap of at least two nearby QDs, and its rate is proportional to the donor-acceptor distance. ${ }^{13}$ Then, the assembly of a close-packed QD monolayer can enhance the interparticle excitonic ET. Langmuir-Blodgett (L.B.) selfassembly using air-water interfaces is a bottom-up method, which can be used for monolayers or multilayers packing of QDs. ${ }^{15-17}$ A major advantage of the L.B. technique is its ability to produce $2 \mathrm{D}$ assemblies with high packing density, in which fast nonradiative ET was observed. ${ }^{18}$ ET and interdot coupling of close-packed silver-, ${ }^{19-22}$ gold-, ${ }^{19,23,24}$ platinum-, ${ }^{25}$ and cadmium-based QDs ${ }^{26-33}$ were reported, and fast ET times around $50 \mathrm{ps}^{34}$ and $90 \mathrm{ps}^{9}$ for $\mathrm{CdSe} / \mathrm{ZnS}$ monolayers were shown. Even though ultrafast nonradiative transfer rates are observed, however, to the best of our knowledge, exciton transfer was not studied in thick-shell QD monolayers. In this study, thin- and thick-shell $\mathrm{InP} / \mathrm{ZnS}$ QDs were chosen to control the donor-acceptor distance and exciton confinement. We synthesized colloidal $\mathrm{InP} / \mathrm{ZnS}$ with one, two, and four shells and then assembled their monolayers with the L.B. technique. We chose indium-based QDs due to the low toxicity compared with cadmium- and lead-based QDs, ${ }^{35-38}$ which may be found in a variety of applications in optoelectronic, ${ }^{39}$ bioelectronic, ${ }^{35,37}$ and energy-harvesting devices. ${ }^{40}$ The radiative lifetime and lifetime distribution of these L.B. monolayers were compared by time-resolved photoluminescence (PL) and fluorescence lifetime imaging microscopy (FLIM) studies. Then, radiative and nonradiative parts of time-resolved charge carrier dynamics were resolved. We investigated the interparticle excitonic energy transfer by spectrally resolved PL dynamics and its normalization using a time-dependent factor. Finally, the average exciton energy of $\mathrm{InP} / 1 \mathrm{ZnS}$, InP/2ZnS, and $\mathrm{InP} / 4 \mathrm{ZnS}$ L.B. monolayers was calculated to compare the ET-induced average exciton energy shift.

\section{METHODS}

Synthesis of Colloidal InP/ZnS QDs and L.B. Monolayer Assembly. We synthesized colloidal InP/ZnS QDs with

Received: January 23, 2018

Revised: $\quad$ May 5, 2018

Published: May 7, 2018 
a
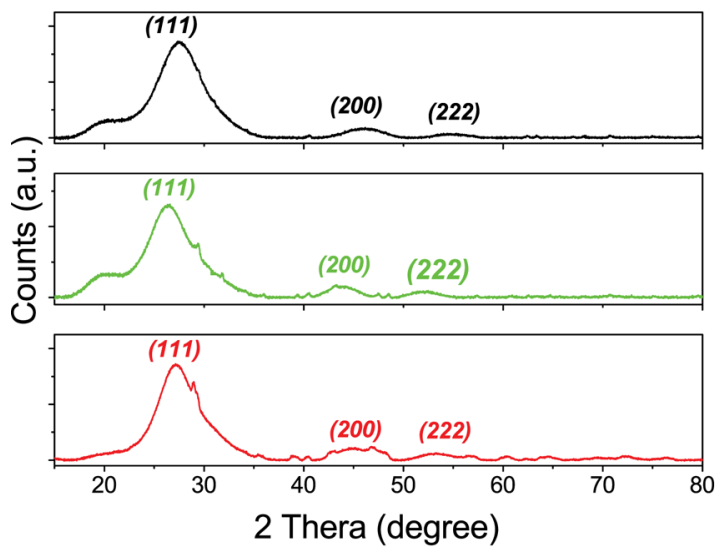

b
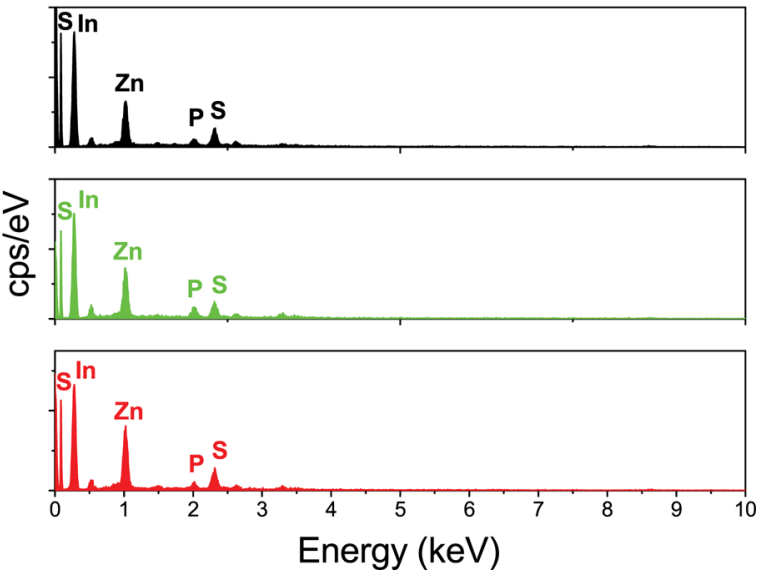

Figure 1. (a) XRD patterns of the InP/1ZnS (black), InP/2ZnS (green), and InP/4ZnS (red) core/shell QDs. (The shoulder beside the (111) plane of InP, may be due to the impurities. ${ }^{41}$ ) (b) EDS results of the InP/1ZnS (black), InP/2ZnS (green), and InP/4ZnS (red) core/shell QDs.

a

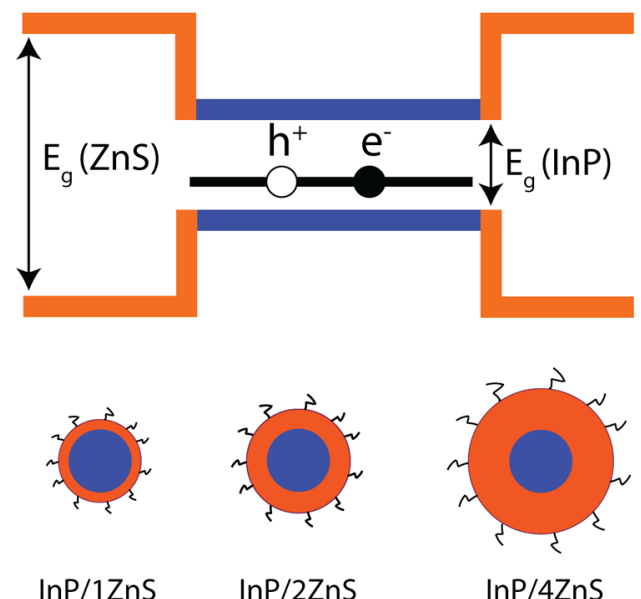

b

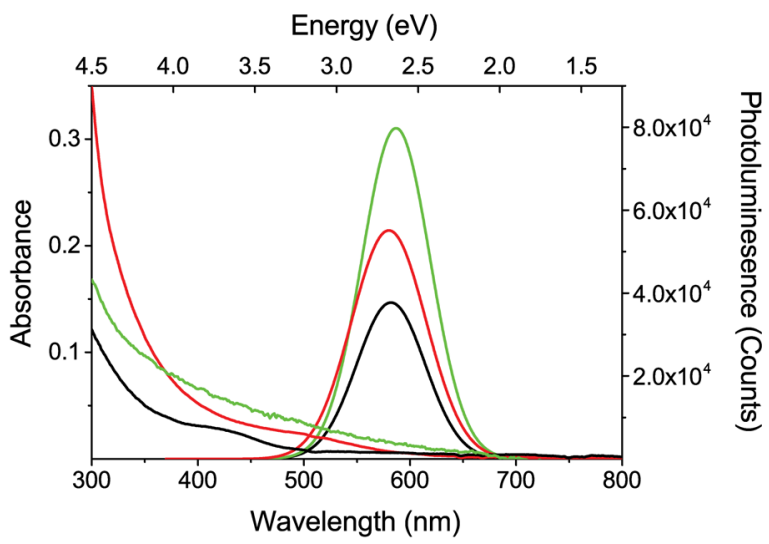

Figure 2. (a) Band alignment of the bulk $\mathrm{InP} / \mathrm{ZnS}$ heterojunction and the schematic representation of the $\mathrm{InP} / 1 \mathrm{ZnS}, \mathrm{InP} / 2 \mathrm{ZnS}$, and $\mathrm{InP} / 4 \mathrm{ZnS}$ core/shell QDs. (b) Steady-state absorbance and PL of the InP/1ZnS (black), InP/2ZnS (green), and InP/4ZnS (red) core/shell QDs dispersed in chloroform.

one, two, and four shells of $\mathrm{ZnS}$ by the hot injection method ${ }^{41}$ (see the Supporting Information for a detailed synthesis procedure). In short, the InP core was synthesized by injection of tris(trimethylsilyl)phosphine $\mathrm{P}(\mathrm{TMS})_{3}$ into indium chloride $\left(\mathrm{InCl}_{3}\right)$ containing solution at the high temperature in the presence of stearic acid (SA) and hexadecylamine (HDA) as ligands. The surface of the InP core was passivated with a zinc carboxylate such as zinc undecylenate to obtain a highly luminescent InP core and improve solubility. ${ }^{41}$ We then thermally decomposed zinc diethyldithiocarbamate to grow $\mathrm{ZnS}$ as the outer shell surrounding the InP core. Finally, we assembled their monolayers on the glass substrate using the L.B. technique (see the Supporting Information for the detailed L.B. assembly procedure.).

\section{RESULTS AND DISCUSSION}

Structural and Optical Analysis of Colloidal InP/ZnS QDs. The X-ray diffraction (XRD) pattern reveals the crystal planes of the (111), (220), and (222) of the InP core (Figure 1a). There is no clear change in peaks after multiple shell growth, which reveals the epitaxial growth of the $\mathrm{ZnS}$ shell. ${ }^{42}$
The peaks of the InP/4ZnS are clearer and sharper than InP/ $1 \mathrm{ZnS}$ showing the uniform growth of the shell with better crystallinity. ${ }^{42}$ Furthermore, energy dispersive spectroscopy (EDS) proves the presence of the indium, phosphorus, zinc, and sulfur elements (Figure $1 \mathrm{~b}$ ). The concentration of the zinc and sulfur increased after epitaxial $\mathrm{ZnS}$ shell growth as expected (Table S1). The TEM study shows a broad particle size distribution for $\mathrm{InP} / 1 \mathrm{ZnS}(3.65 \mathrm{~nm} \pm 0.42)$ (Figure $\mathrm{S} 1$ ).

The QY of the colloidal Type-I InP/1ZnS, InP/2ZnS, and $\mathrm{InP} / 4 \mathrm{ZnS}$ are $12.6 \pm 1.8 \%, 43.1 \pm 3.4 \%$, and $14.7 \pm 1.5 \%$, respectively (Figure 2a). Before L.B. assembly of QDs in 2D, we investigated their steady-state optical properties in solution form (dispersed in chloroform) (Figure 2b). The steady-state absorbance shows an increase of the absorbance peak corresponding to the thicker $\mathrm{ZnS}$ formation like in $\mathrm{CdSe}$ QDs. ${ }^{43}$ The PL full width of half-maximum (fwhm) of InP/ $4 \mathrm{ZnS}(\sim 90 \mathrm{~nm})$ is slightly larger than $\mathrm{InP} / 1 \mathrm{ZnS}(\sim 80 \mathrm{~nm})$ and $\mathrm{InP} / 2 \mathrm{ZnS}(\sim 80 \mathrm{~nm})$, which is possibly due to the straininduced inhomogeneous emission broadening. ${ }^{42,44}$

Assembly of L.B. Monolayers. After spreading of the QD solution on the water medium, the QDs self-assembles into 
micro- and macroscopic monolayer islands. ${ }^{45}$ Compressing this film leads to a transition from islands to a close-packed full monolayer. ${ }^{46}$ The isotherms, which presented as surface pressure versus trough area, ${ }^{47}$ monitor subsequent expansion and recompression of the floating QD monolayers (Figure 3a).
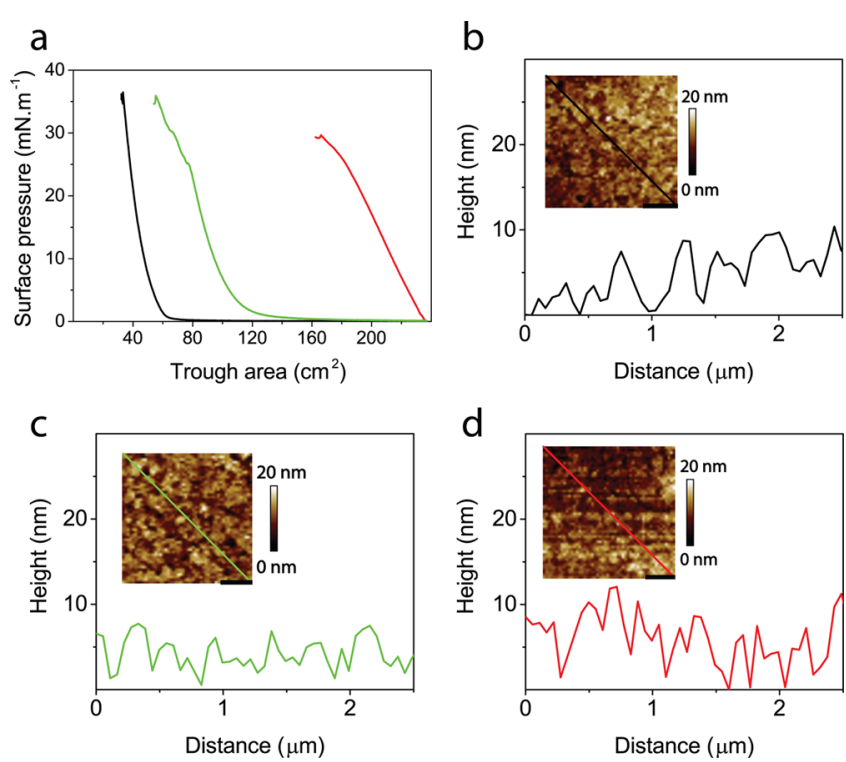

Figure 3. (a) Isotherms obtained during monolayer compression of the InP/1ZnS (black), InP/2ZnS (green), and InP/4ZnS (red) core/ shell QDs. Depth profile and AFM images (inset) of (b) InP/1ZnS, (c) InP/2ZnS, and (d) InP/4ZnS L.B. monolayers.

The transition regime from monolayer islands to full monolayer is shorter for larger sized $\mathrm{InP} / 4 \mathrm{ZnS}$. The monolayer collapses at a surface pressure of 38,37 , and $32 \mathrm{mN} \cdot \mathrm{m}^{-1}$ for $\mathrm{InP} / 1 \mathrm{ZnS}$, $\mathrm{InP} / 2 \mathrm{ZnS}$, and $\mathrm{InP} / 4 \mathrm{ZnS}$, respectively. We chose to deposit the monolayer at the surface pressure, of 36,35 , and $30 \mathrm{mN}$. $\mathrm{m}^{-1}$ for $\mathrm{InP} / 1 \mathrm{ZnS}, \mathrm{InP} / 2 \mathrm{ZnS}$, and $\mathrm{InP} / 4 \mathrm{ZnS}$, respectively, which are below the collapse pressure but within the closepacked monolayer regime. Atomic force microscopy (AFM) images of the L.B. monolayers show voidless and smooth surfaces compared to drop-casted or dip-coated films as reported in the literature ${ }^{48}$ (Figure $3 b-d$ ). The surface roughness values of all samples are below $3 \mathrm{~nm}$ (Table S2).

Time-Resolved Charge-Carrier Dynamics in InP/ZnS L.B. Assembly. To investigate the interparticle ET dynamics of QD L.B. monolayers, first we opted to understand the mechanism of the charge-carrier dynamics in QD 2D assemblies by considering their intrinsic optical properties and close-packed orientation (Figure 4a). Some studies assumed only radiative decays $\left(k_{\text {rad }}\right)$ for QDs, ${ }^{49}$ but defects creating nonradiative decay rate $\left(k_{\mathrm{nr}}\right)$ need to be considered. ${ }^{50}$ Additionally, due to the close-packed orientation, it is expected to see an extra nonradiative rate coming from excitonic ET within particles $\left(k_{\mathrm{et}}\right)$. We used the general methodology of time-resolved photoluminescence (TRPL) via a time-correlated single-photon counting (TCSPC). All L.B. monolayers were excited by a nanosecond pulsed laser $(\lambda=375 \mathrm{~nm})$, and their PL decay was recorded. (See the Supporting Information for detailed instrumentation.) PL decays were fit by a twoexponential decay, ${ }^{30}$ and the average lifetime $\left(\tau_{\text {avg }}\right)$ was calculated from an amplitude weighted mean (eq 1).

$$
\tau_{\mathrm{avg}}=\frac{A_{1} \tau_{1}^{2}+A_{2} \tau_{2}^{2}}{A_{1} \tau_{1}+A_{2} \tau_{2}}
$$

The longest component of the measured PL decay $\left(\tau_{1}\right)$ is a lower limit for radiative lifetime $\left(\tau_{\text {rad }}\right)$ due to the presence of the surface traps and delayed fluorescence occurs because of the reversible populations of the traps. ${ }^{50}$ We measured the QY of the L.B. monolayers by an integrated sphere to estimate the radiative lifetime (eq 2). ${ }^{50}$ The results show a decrease in radiative lifetime after multiple shelling of $\mathrm{ZnS}$ (Table. 1) like reported for CdTe QDs, ${ }^{50}$ which can be due to the increasing of the extinction coefficient. The increase of the extinction coefficient after multiple shelling agrees with the steady-state absorbance data (Figure 2b), as well.

$$
\tau_{\text {rad }}=\frac{\tau_{\text {avg }}}{\mathrm{QY}}
$$

Afterward, fluorescence lifetime imaging (FLIM) studies were done on the L.B. monolayers to examine the lifetime distribution in 2D. FLIM is a useful spatial analysis tool for QDs due to their long fluorescence lifetime ${ }^{51}$ and resistance to photobleaching. ${ }^{52}$ The FLIM images of $\mathrm{InP} / 1 \mathrm{ZnS}$ and $\mathrm{InP} /$ $2 \mathrm{ZnS}$ L.B. monolayers (Figure 5a,b) show a broad lifetime distribution compared to $\mathrm{InP} / 4 \mathrm{ZnS}$ (Figure 5c), which proves stronger nonradiative energy transfers in thin-shell QD assemblies. Long donor-acceptor distance and strong exciton confinement may lead to narrowing the lifetime distribution in the InP/4ZnS L.B. assembly.

Excitonic ET Dynamics in InP/ZnS L.B. Monolayers. Energy transfer occurs by electrostatic interaction between the emission dipole moments of an exciton generated in the donor with the absorption dipole moment of the acceptor in $\mathrm{QD}$ assemblies. The exciton transfer between two similarly sized QDs is not efficient due to the weak coupling regime. However, in our case, due to the wide PL fwhm $(\sim 70 \mathrm{~nm})$, the emitting
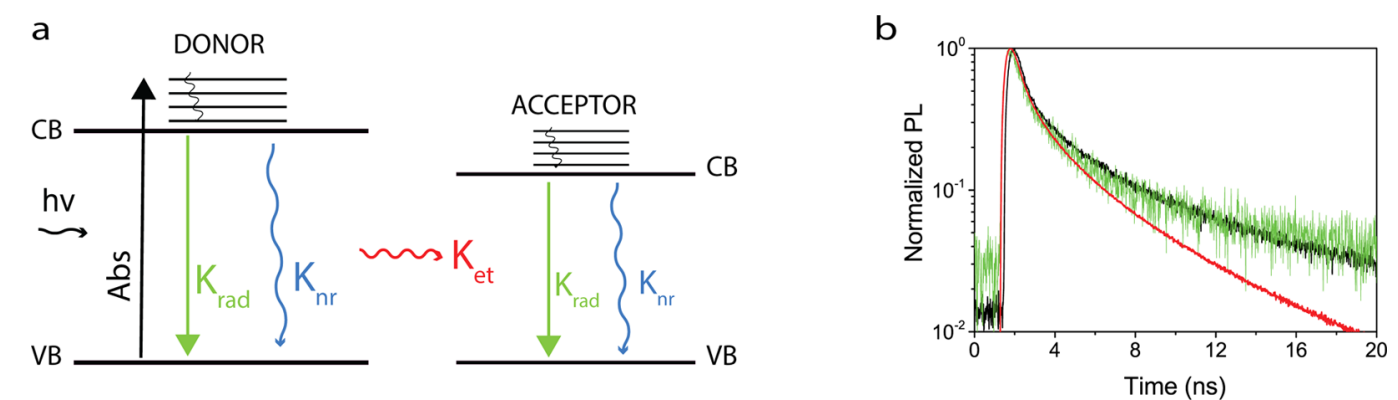

Figure 4. (a) Suggested charge-carrier recombination mechanism for the InP/ZnS L.B. monolayer. (b) Time decays of the InP/1ZnS (black), InP/ $2 \mathrm{ZnS}$ (green), and InP/4ZnS (red) L.B. monolayers. 
Table 1. PL Decay analysis of InP/1ZnS, InP/2ZnS, and InP/4ZnS L.B. Monolayers

\begin{tabular}{|c|c|c|c|c|c|c|c|c|}
\hline sample & $A_{1}$ (kCnts) & $\mathrm{A}_{2}$ (kCnts) & $\mathrm{A}_{\mathrm{SUM}}(\mathrm{kCnts})$ & $\tau_{1}(\mathrm{~ns})$ & $\tau_{2}(\mathrm{~ns})$ & $\tau_{\text {avg }}(\mathrm{ns})$ & Q.Y. (\%) & $\tau_{\mathrm{rad}}(\mathrm{ns})$ \\
\hline $\operatorname{InP} / \mathbf{1 Z n S}$ & $12.18 \pm 0.14$ & $3.98 \pm 0.05$ & $48 \pm 1.3$ & $4.66 \pm 0.05$ & $0.66 \pm 0.008$ & $0.56 \pm 0.02$ & $0.95 \pm 0.13$ & 58.9 \\
\hline $\operatorname{InP} / 2 \mathrm{ZnS}$ & $2.89 \pm 0.04$ & $3.77 \pm 0.21$ & $6.66 \pm 0.31$ & $2.67 \pm 0.003$ & $0.59 \pm 0.007$ & $1.49 \pm 0.021$ & $3.18 \pm 0.06$ & 46.8 \\
\hline $\operatorname{InP} / 4 \mathrm{ZnS}$ & $266.6 \pm 3.2$ & $96.6 \pm 1.4$ & $3134 \pm 120$ & $4.022 \pm 0.014$ & $0.768 \pm 0.005$ & $0.208 \pm 0.007$ & $1.35 \pm 0.07$ & 15.4 \\
\hline
\end{tabular}

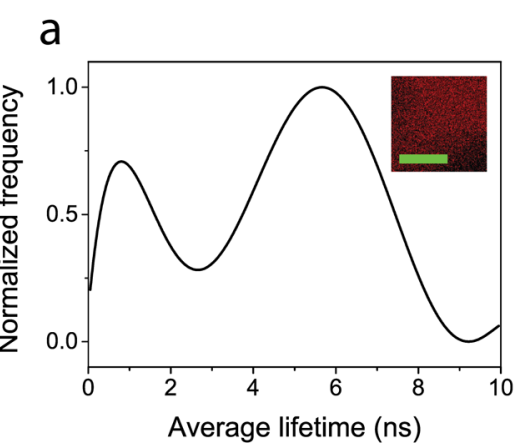

\section{b}

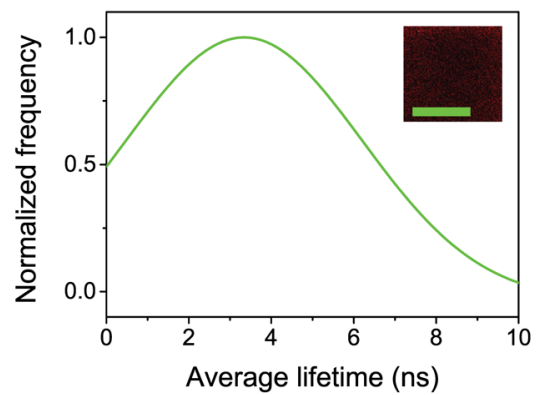

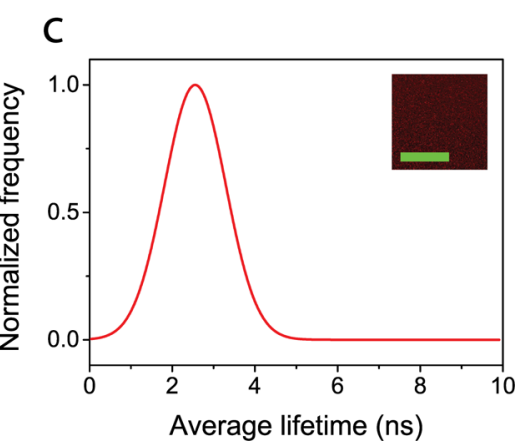

Figure 5. Average lifetime histogram and FLIM images (inset) of (a) InP/1ZnS, (b) InP/2ZnS, and (c) InP/4ZnS L.B. monolayers (bar: $5 \mu$ m).
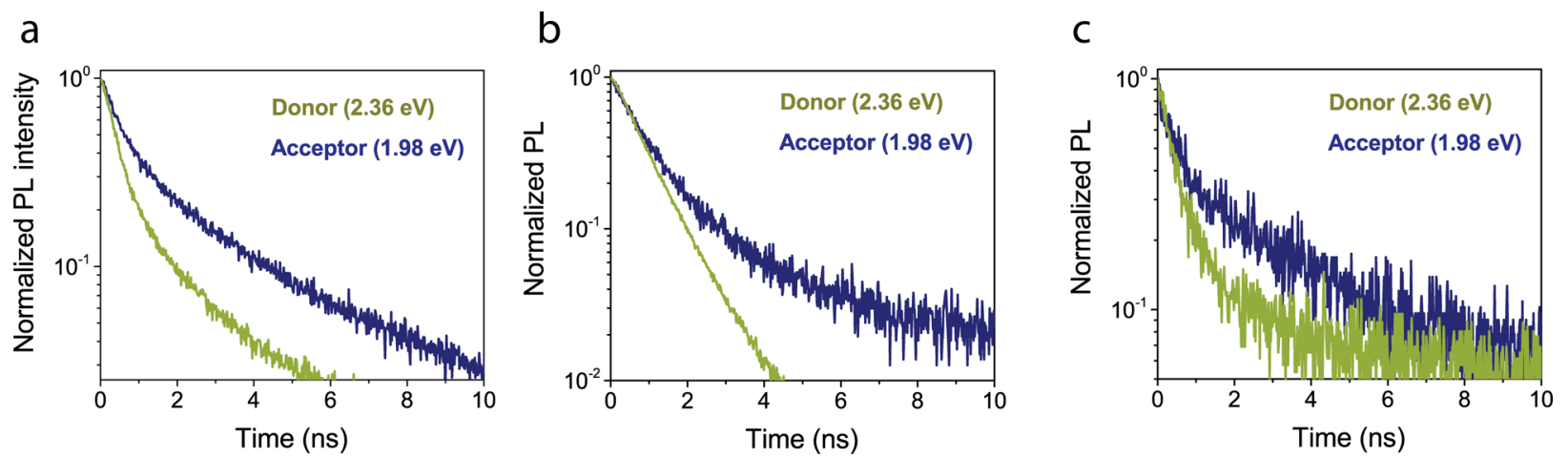

Figure 6. PL decays of (a) InP/1ZnS, (b) InP/2ZnS, and (c) InP/4ZnS L.B. monolayers measured under detection wavelengths of 525 and $625 \mathrm{~nm}$.
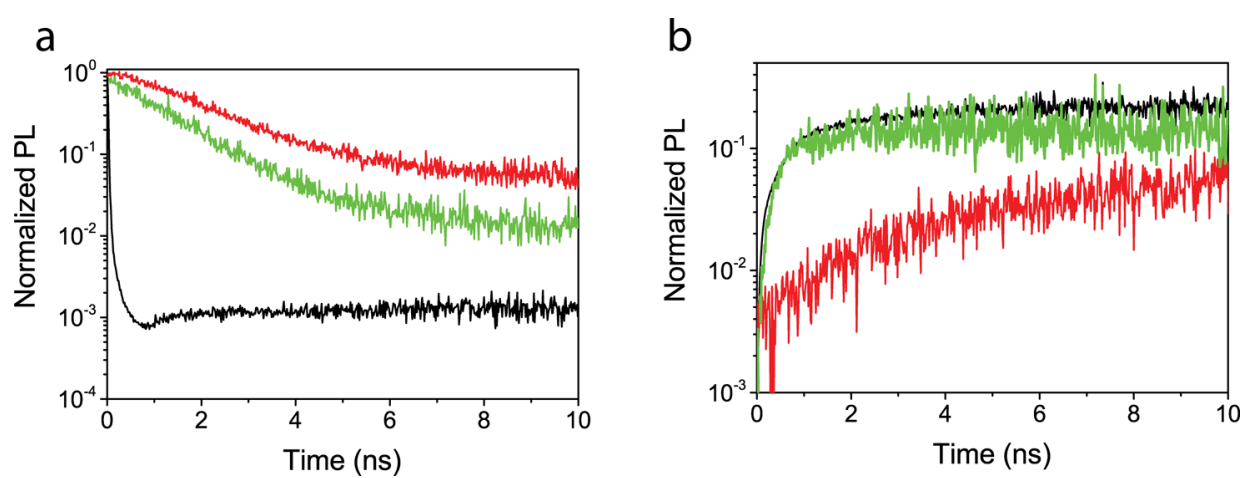

Figure 7. Normalized PL decays of the InP/1ZnS (black), InP/2ZnS (green), and InP/4ZnS (red) L.B. monolayers by time-dependent factor under detection wavelengths of (a) $525 \mathrm{~nm}$ and (b) $625 \mathrm{~nm}$.

transition of a donor can be resonated with a strong absorbing transition of an acceptor and generates strong coupling regime. $^{34}$ The ET rate can be estimated using the Förster expression $^{13}$ (eq 3) in which $\mu_{\mathrm{D}}$ and $\mu_{\mathrm{A}}$ are the donor and acceptor dipole moments, $r$ is the donor-acceptor separation, $\Theta$ is the overlap integral between normalized donor emission and acceptor absorption spectra, $\kappa^{2}$ is an orientational factor (for random dipole orientation $\kappa^{2}=2 / 3$ ), and $n$ is the refractive index of the medium. We changed the donor-acceptor distance by controlling shell thickness.

$$
k_{\mathrm{et}}=\frac{2 \pi}{h} \frac{\mu_{\mathrm{D}}^{2} \mu_{\mathrm{A}}^{2} \kappa^{2}}{r^{6} n^{4}} \Theta
$$

We assembled QDs in close-packed 2D to increase their packing density and provide more number of potential acceptors in the first shell of the donor. To study the exciton migration from small QDs to large QDs, first we measured the PL decay under different spectral detection energies using filters from 430 to $700 \mathrm{~nm}$. Donor and acceptor detection wavelengths were set as $525 \mathrm{~nm}(2.36 \mathrm{eV})$ and $625 \mathrm{~nm}(1.98$ $\mathrm{eV}$ ) considering the steady-state PL, respectively (Figure $2 \mathrm{~b}$ ). 
Spectrally resolved PL dynamics reveal faster decays for donors (Figure 6), which indicates the migration of the exciton from small QDs to large QDs. ${ }^{34,53}$

To understand the exciton ET dynamics, we extracted the radiative and nonradiative recombination from spectrally resolved PL decays using a time-dependent factor (eq 4)..$^{34}$ This factor is proportional to the total number of the excitons showing the exciton recombination dynamics from both radiative and nonradiative processes.

$$
\beta(t)=\int_{0}^{\infty} I(\omega, t) \mathrm{d} \omega
$$

The normalized spectrally resolved PL traces show a PL decrease for donors (Figure 7a) and PL growth for acceptors (Figure $7 \mathrm{~b}$ ). It proves the exciton transfer from small QDs to large QDs due to the nonradiative excitonic ET. But the excitonic ET of the $\mathrm{InP} / 4 \mathrm{ZnS}$ monolayer is lower than $\mathrm{InP} /$ $1 \mathrm{ZnS}$ and $\mathrm{InP} / 2 \mathrm{ZnS}$ monolayers due to the longer donoracceptor distance and strong exciton confinement.

Finally, we calculated the average exciton energy to see the effect of shell thickness on exciton flow using spectrally resolved PL data (eq 5). The energy-transfer-induced shift in the average exciton energy of $\mathrm{InP} / 1 \mathrm{ZnS}(95 \mathrm{meV})$ is higher than that of $\mathrm{InP} / 2 \mathrm{ZnS}(52 \mathrm{meV})$ and $\mathrm{InP} / 4 \mathrm{ZnS}(27 \mathrm{meV})$, which shows lower exciton $\mathrm{ET}$ in $\mathrm{InP} / 4 \mathrm{ZnS}$ in comparison with $\mathrm{InP} / 1 \mathrm{ZnS}$ (Figure 8). Although $\mathrm{InP} / 2 \mathrm{ZnS}$ has lower $\mathrm{QY}$ than

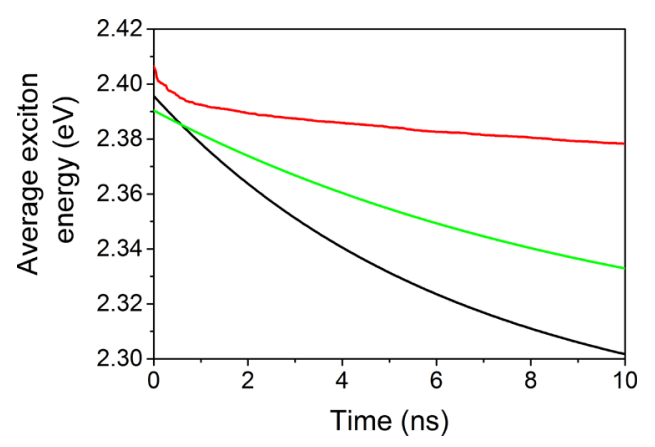

Figure 8. Calculated average exciton energy of the $\mathrm{InP} / 1 \mathrm{ZnS}$ (black), $\mathrm{InP} / 2 \mathrm{ZnS}$ (green), and $\mathrm{InP} / 4 \mathrm{ZnS}$ (red) L.B. assemblies.

$\mathrm{InP} / 1 \mathrm{ZnS}$ (Table 1 ), its nonradiative ET is lower due to the longer donor-acceptor distance. Dropcasted CdSe QDs showed lower shift $(30 \mathrm{meV})$ compared with CdSe QD L.B. assemblies $(55 \mathrm{meV})$ due to lower packing density, ${ }^{34}$ but our lower energy shift comes from the thick shell surrounding the core and longer donor-acceptor distance. We showed that the excitonic ET of $\mathrm{InP} / \mathrm{ZnS}$ QD monolayer can be strongly influenced by the shell thickness. Having a thick-shell QD, we decreased the ET-induced average exciton energy shift by a factor of 4 in L.B. assemblies.

$$
\langle E(t)\rangle=\beta^{-1}(t) \int_{0}^{\infty} h \omega I(\omega, t) \mathrm{d} \omega
$$

\section{CONCLUSION}

In summary, $\mathrm{InP} / 1 \mathrm{ZnS}, \mathrm{InP} / 2 \mathrm{ZnS}$, and $\mathrm{InP} / 4 \mathrm{ZnS}$ colloidal QDs were synthesized via a hot injection method. The XRD results proved the existence of the $\mathrm{InP} / \mathrm{ZnS}$ crystal structure and successful multiple shell growth. The presence of the indium, phosphorus, zinc, and sulfur elements was shown by EDS. The L.B. technique was used to assemble monolayers of
InP/1ZnS, InP/2ZnS, and InP/4ZnS. The AFM profiles show a smooth surface for all assembled L.B. monolayers. FLIM studies suggest strong exciton confinement and narrow lifetime distribution for $\mathrm{InP} / 4 \mathrm{ZnS}$. Spectrally resolved PL decays show faster decays for donors in all $\mathrm{InP} / \mathrm{ZnS}$ assemblies. The exciton migration from donor to acceptor was confirmed by the spectrally resolved PL decay normalized by a time-dependent factor. The exciton transfer in thick-shell $\mathrm{InP} / 4 \mathrm{ZnS}$ is much lower than that in $\mathrm{InP} / 1 \mathrm{ZnS}$ due to the thicker shell and longer donor-acceptor distance. The ET-induced average exciton energy shift is decreased by a factor of 4 after multiple shelling of $\mathrm{ZnS}$. The controlled ET in biocompatible QD assemblies can open up new features in FRET-based biological applications.

\section{ASSOCIATED CONTENT}

\section{Supporting Information}

The Supporting Information is available free of charge on the ACS Publications website at DOI: 10.1021/acs.jpcc.8b00744.

Tables S1 and S2 and Figure S1 (PDF)

\section{AUTHOR INFORMATION}

\section{Corresponding Author}

*E-mail: snizamoglu@ku.edu.tr.

ORCID ${ }^{\circ}$

Houman Bahmani Jalali: 0000-0001-7212-9098

Rustamzhon Melikov: 0000-0003-2214-7604

Sadra Sadeghi: 0000-0002-8569-1626

Sedat Nizamoglu: 0000-0003-0394-5790

Notes

The authors declare no competing financial interest.

\section{ACKNOWLEDGMENTS}

This project has received funding from the European Research Council (ERC) under the European Union's Horizon 2020 research and innovation programme (Grant Agreement No. 639846). We thank KUYTAM (Koç University Surface Science and Technology Center) for Langmuir-Blodgett, XRD, EDS, and AFM infrastructures. The authors gratefully acknowledge Dr. Baris Yagci for EDS, Dr. Ceren Yilma Akkayaz for XRD, and Dr. Amir Motallebzadeh for AFM measurements.

\section{REFERENCES}

(1) Medintz, I. L.; Uyeda, H. T.; Goldman, E. R.; Mattoussi, H. Quantum Dot Bioconjugates for Imaging, Labelling and Sensing. Nat. Mater. 2005, 4, 435.

(2) Medintz, I. L.; Mattoussi, H. Quantum Dot-Based Resonance Energy Transfer and Its Growing Application in Biology. Phys. Chem. Chem. Phys. 2009, 11, 17-45.

(3) Medintz, I. L.; Clapp, A. R.; Brunel, F. M.; Tiefenbrunn, T.; Tetsuo Uyeda, H.; Chang, E. L.; Deschamps, J. R.; Dawson, P. E.; Mattoussi, H. Proteolytic Activity Monitored by Fluorescence Resonance Energy Transfer through Quantum-Dot-Peptide Conjugates. Nat. Mater. 2006, 5, 581.

(4) Brédas, J.-L.; Sargent, E. H.; Scholes, G. D. Photovoltaic Concepts Inspired by Coherence Effects in Photosynthetic Systems. Nat. Mater. 2017, 16, 35.

(5) Yao, H.; Zhang, Y.; Xiao, F.; Xia, Z.; Rao, Z. Quantum Dot/ Bioluminescence Resonance Energy Transfer Based Highly Sensitive Detection of Proteases. Angew. Chem., Int. Ed. 2007, 46, 4346-4349.

(6) Clapp, A. R.; Medintz, I. L.; Mauro, J. M.; Fisher, B. R.; Bawendi, M. G.; Mattoussi, H. Fluorescence Resonance Energy Transfer between Quantum Dot Donors and Dye-Labeled Protein Acceptors. J. Am. Chem. Soc. 2004, 126, 301-310. 
(7) Clapp, A. R.; Medintz, I. L.; Mattoussi, H. Förster Resonance Energy Transfer Investigations Using Quantum-Dot Fluorophores. ChemPhysChem 2006, 7, 47-57.

(8) Willard, D. M.; Carillo, L. L.; Jung, J.; Van Orden, A. CdSe-Zns Quantum Dots as Resonance Energy Transfer Donors in a Model Protein-Protein Binding Assay. Nano Lett. 2001, 1, 469-474.

(9) Achermann, M.; Jeong, S.; Balet, L.; Montano, G. A.; Hollingsworth, J. A. Efficient Quantum Dot-Quantum Dot and Quantum Dot-Dye Energy Transfer in Biotemplated Assemblies. ACS Nano 2011, 5, 1761-1768.

(10) Samia, A. C. S.; Dayal, S.; Burda, C. Quantum Dot-Based Energy Transfer: Perspectives and Potential for Applications in Photodynamic Therapy. Photochem. Photobiol. 2006, 82, 617-625.

(11) Press, D. A.; Melikov, R.; Conkar, D.; Firat-Karalar, E. N.; Nizamoglu, S. Fluorescent Protein Integrated White LEDs for Displays. Nanotechnology 2016, 27, 45LT01.

(12) Lakowicz, J. R. Principles of Fluorescence Spectroscopy; Springer Science \& Business Media, 2013.

(13) Förster, T. Energy Transfer and Fluorescence between Molecules. Ann. Phys. 1948, 437, 55-75.

(14) Wu, J.; Liu, F.; Shen, Y.; Cao, J.; Silbey, R. J. Efficient Energy Transfer in Light-Harvesting Systems, I: Optimal Temperature, Reorganization Energy and Spatial-Temporal Correlations. New J. Phys. 2010, 12, 105012 .

(15) Kotov, N. A.; Meldrum, F. C.; Wu, C.; Fendler, J. H. Monoparticulate Layer and Langmuir-Blodgett-Type Multiparticulate Layers of Size-Quantized Cadmium Sulfide Clusters: A ColloidChemical Approach to Superlattice Construction. J. Phys. Chem. 1994, 98, 2735-2738.

(16) Meldrum, F. C.; Kotov, N. A.; Fendler, J. H. Utilization of Surfactant-Stabilized Colloidal Silver Nanocrystallites in the Construction of Mono- and Multiparticulate Langmuir-Blodgett Films. Langmuir 1994, 10, 2035-2040.

(17) Nakaya, T.; Li, Y.-J.; Shibata, K. Preparation of Ultrafine Particle Multilayers Using the Langmuir-Blodgett Technique. J. Mater. Chem. 1996, 6, 691-697.

(18) Malhotra, S.; Prasad, B.; Fraxedas, J. Molecular Materials: Preparation, Characterization, and Applications; CRC Press, 2017.

(19) Heath, J. R.; Knobler, C. M.; Leff, D. V. Pressure/Temperature Phase Diagrams and Superlattices of Organically Functionalized Metal Nanocrystal Monolayers: The Influence of Particle Size, Size Distribution, and Surface Passivant. J. Phys. Chem. B 1997, 101, 189-197.

(20) Collier, C. P.; Saykally, R. J.; Shiang, J. J.; Henrichs, S. E.; Heath, J. R. Reversible Tuning of Silver Quantum Dot Monolayers through the Metal-Insulator Transition. Science 1997, 277, 1978-1981.

(21) Chung, S. W.; Markovich, G.; Heath, J. R. Fabrication and Alignment of Wires in Two Dimensions. J. Phys. Chem. B 1998, 102, 6685-6687.

(22) Sastry, M.; Mayya, K. S.; Patil, V.; Paranjape, D. V.; Hegde, S. G. Langmuir-Blodgett Films of Carboxylic Acid Derivatized Silver Colloidal Particles: Role of Subphase $\mathrm{Ph}$ on Degree of Cluster Incorporation. J. Phys. Chem. B 1997, 101, 4954-4958.

(23) Fujihira, M. Photoinduced Electron Transfer and Energy Transfer in Langmuir-Blodgett Films. In Molecular and Biomolecular Electronics. Adv. Chem. Ser. 1994, 240, 373-394.

(24) Sastry, M.; Gole, A.; Patil, V. Lamellar Langmuir-Blodgett Films of Hydrophobized Colloidal Gold Nanoparticles by Organization at the Air-Water Interface. Thin Solid Films 2001, 384, 125131.

(25) Meldrum, F. C.; Kotov, N. A.; Fendler, J. H. Formation of Thin Films of Platinum, Palladium, and Mixed Platinum: Palladium Nanocrystallites by the Langmuir Monolayer Technique. Chem. Mater. 1995, 7, 1112-1116.

(26) Dabbousi, B. O.; Murray, C. B.; Rubner, M. F.; Bawendi, M. G. Langmuir-Blodgett Manipulation of Size-Selected Cdse Nanocrystallites. Chem. Mater. 1994, 6, 216-219.

(27) Gattás-Asfura, K. M.; Constantine, C. A.; Lynn, M. J.; Thimann, D. A.; Ji, X.; Leblanc, R. M. Characterization and 2D Self-Assembly of
CdSe Quantum Dots at the Air-Water Interface. J. Am. Chem. Soc. 2005, 127, 14640-14646.

(28) Cordero, S. R.; Carson, P. J.; Estabrook, R. A.; Strouse, G. F.; Buratto, S. K. Photo-Activated Luminescence of CdSe Quantum Dot Monolayers. J. Phys. Chem. B 2000, 104, 12137-12142.

(29) Ji, X.; Wang, C.; Xu, J.; Zheng, J.; Gattás-Asfura, K. M.; Leblanc, R. M. Surface Chemistry Studies of $(\mathrm{CdSe}) \mathrm{ZnS}$ Quantum Dots at the Air-Water Interface. Langmuir 2005, 21, 5377-5382.

(30) Lunz, M.; Bradley, A. L.; Gerard, V. A.; Byrne, S. J.; Gun'ko, Y. K.; Lesnyak, V.; Gaponik, N. Concentration Dependence of Förster Resonant Energy Transfer between Donor and Acceptor Nanocrystal Quantum Dot Layers: Effect of Donor-Donor Interactions. Phys. Rev. B: Condens. Matter Mater. Phys. 2011, 83, 115423.

(31) Kagan, C. R.; Murray, C. B.; Nirmal, M.; Bawendi, M. G. Electronic Energy Transfer in CdSe Quantum Dot Solids. Phys. Rev. Lett. 1996, 76, 1517-1520.

(32) Kagan, C. R.; Murray, C. B.; Bawendi, M. G. Long-Range Resonance Transfer of Electronic Excitations in Close-Packed CdSe Quantum-Dot Solids. Phys. Rev. B: Condens. Matter Mater. Phys. 1996, 54, 8633-8643.

(33) Collier, C. P.; Vossmeyer, T.; Heath, J. R. Nanocrystal Superlattices. Annu. Rev. Phys. Chem. 1998, 49, 371-404.

(34) Achermann, M.; Petruska, M. A.; Crooker, S. A.; Klimov, V. I. Picosecond Energy Transfer in Quantum Dot Langmuir-Blodgett Nanoassemblies. J. Phys. Chem. B 2003, 107, 13782-13787.

(35) Lin, G.; Ouyang, Q.; Hu, R.; Ding, Z.; Tian, J.; Yin, F.; Xu, G.; Chen, Q.; Wang, X.; Yong, K.-T. In Vivo Toxicity Assessment of NonCadmium Quantum Dots in Balb/C Mice. Nanomedicine 2015, 11, 341-350.

(36) Chibli, H.; Carlini, L.; Park, S.; Dimitrijevic, N. M.; Nadeau, J. L. Cytotoxicity of InP/ZnS Quantum Dots Related to Reactive Oxygen Species Generation. Nanoscale 2011, 3, 2552-2559.

(37) Brunetti, V.; Chibli, H.; Fiammengo, R.; Galeone, A.; Malvindi, M. A.; Vecchio, G.; Cingolani, R.; Nadeau, J. L.; Pompa, P. P. InP/ZnS as a Safer Alternative to CdSe/ZnS Core/Shell Quantum Dots: In Vitro and in Vivo Toxicity Assessment. Nanoscale 2013, 5, 307-317.

(38) Michalet, X.; Pinaud, F. F.; Bentolila, L. A.; Tsay, J. M.; Doose, S.; Li, J. J.; Sundaresan, G.; Wu, A. M.; Gambhir, S. S.; Weiss, S. Quantum Dots for Live Cells, in Vivo Imaging, and Diagnostics. Science 2005, 307, 538-544.

(39) Demir, H. V.; Nizamoglu, S.; Erdem, T.; Mutlugun, E.; Gaponik, N.; Eychmüller, A. Quantum Dot Integrated LEDs Using Photonic and Excitonic Color Conversion. Nano Today 2011, 6, 632-647.

(40) Sadeghi, S.; Bahmani Jalali, H.; Melikov, R.; Ganesh Kumar, B.; Mohammadi Aria, M.; Ow-Yang, C. W.; Nizamoglu, S. Stokes-ShiftEngineered Indium Phosphide Quantum Dots for Efficient Luminescent Solar Concentrators. ACS Appl. Mater. Interfaces 2018, 10, 12975-12982.

(41) Xu, S.; Ziegler, J.; Nann, T. Rapid Synthesis of Highly Luminescent Inp and InP/ZnS Nanocrystals. J. Mater. Chem. 2008, 18, $2653-2656$.

(42) Shen, W.; Tang, H.; Yang, X.; Cao, Z.; Cheng, T.; Wang, X.; Tan, Z.; You, J.; Deng, Z. Synthesis of Highly Fluorescent InP/ZnS Small-Core/Thick-Shell Tetrahedral-Shaped Quantum Dots for Blue Light-Emitting Diodes. J. Mater. Chem. C 2017, 5, 8243-8249.

(43) Fu, Y.; Kim, D.; Jiang, W.; Yin, W.; Ahn, T. K.; Chae, H. Excellent Stability of Thicker Shell CdSe@ZnS/ZnS Quantum Dots. RSC Adv. 2017, 7, 40866-40872.

(44) Rubin-Brusilovski, A.; Jang, Y.; Shapiro, A.; Safran, A.; Sashchiuk, A.; Lifshitz, E. Influence of Interfacial Strain on Optical Properties of $\mathrm{PbSe} / \mathrm{PbS}$ Colloidal Quantum Dots. Chem. Mater. 2016, 28, 9056-9063.

(45) Lambert, K.; Čapek, R. K.; Bodnarchuk, M. I.; Kovalenko, M. V.; Van Thourhout, D.; Heiss, W.; Hens, Z. Langmuir-Schaefer Deposition of Quantum Dot Multilayers. Langmuir 2010, 26, 77327736.

(46) Lambert, K.; Justo, Y.; Kamal, J. S.; Hens, Z. Phase Transitions in Quantum-Dot Langmuir Films. Angew. Chem., Int. Ed. 2011, 50, 12058-12061. 
(47) Paul, S.; Pearson, C.; Molloy, A.; Cousins, M. A.; Green, M.; Kolliopoulou, S.; Dimitrakis, P.; Normand, P.; Tsoukalas, D.; Petty, M. C. Langmuir-Blodgett Film Deposition of Metallic Nanoparticles and Their Application to Electronic Memory Structures. Nano Lett. 2003, 3, 533-536.

(48) Lambert, K.; Wittebrood, L.; Moreels, I.; Deresmes, D.; Grandidier, B.; Hens, Z. Langmuir-Blodgett Monolayers of InP Quantum Dots with Short Chain Ligands. J. Colloid Interface Sci. 2006, $300,597-602$.

(49) de Mello Donegá, C.; Koole, R. Size Dependence of the Spontaneous Emission Rate and Absorption Cross Section of CdSe and CdTe Quantum Dots. J. Phys. Chem. C 2009, 113, 6511-6520.

(50) Gong, K.; Zeng, Y.; Kelley, D. F. Extinction Coefficients, Oscillator Strengths, and Radiative Lifetimes of CdSe, CdTe, and CdTe/CdSe Nanocrystals. J. Phys. Chem. C 2013, 117, 20268-20279.

(51) Durisic, N.; Godin, A. G.; Walters, D.; Grütter, P.; Wiseman, P. W.; Heyes, C. D. Probing the "Dark" Fraction of Core-Shell Quantum Dots by Ensemble and Single Particle Ph-Dependent Spectroscopy. ACS Nano 2011, 5, 9062-9073.

(52) Orte, A.; Alvarez-Pez, J. M.; Ruedas-Rama, M. J. Fluorescence Lifetime Imaging Microscopy for the Detection of Intracellular $\mathrm{Ph}$ with Quantum Dot Nanosensors. ACS Nano 2013, 7, 6387-6395.

(53) Crooker, S. A.; Hollingsworth, J. A.; Tretiak, S.; Klimov, V. I. Spectrally Resolved Dynamics of Energy Transfer in Quantum-Dot Assemblies: Towards Engineered Energy Flows in Artificial Materials. Phys. Rev. Lett. 2002, 89, 186802. 